\title{
Purificação e reutilização de águas residuárias da produção de biodiesel por meio da eletrofloculação
}

\section{Ramon Borges Cordeiro ${ }^{1 * *}$, Jeisiane Isabella da Silva Alexandre', João Pedro Ferreira Silva ${ }^{1}$, Deivson Cesar Silva Sales ${ }^{2}$, Luiz Antônio Pimentel Cavalcanti ${ }^{3}$}

${ }^{1}$ Associação Caruaruense de Ensino Superior e Técnico, Av. Portugal, 584, Bairro Universitário, Caruaru-PE (CEP 55016-400). Estudante de Graduando em Engenharia Ambiental.*E-mail: ramon_gratz@hotmail.com.

${ }^{2}$ Associação Caruaruense de Ensino Superior e Técnico, Av. Portugal, 584, Bairro Universitário, Caruaru-PE (CEP 55016-400). Professor Auxiliar I.

E-mail: deivsoncesar@yahoo.com.br.

${ }^{3}$ Instituto Federal de Educação, Ciência e Tecnologia da Bahia, Campus de Paulo Afonso, Rua Marcondes Ferraz, 200, Bairro General Dutra, Paulo Afonso-BA (CEP 48607-000). Professor do Ensino Básico, Técnico e Tecnológico (EBTT).

Resumo. Dentre os resíduos gerados na produção de biodiesel, as águas residuais aparecem em lugar de destaque. Essas águas apresentam em sua composição principalmente glicerina, álcool, traços do catalisador entre outros contaminantes, que impedem seu descarte nos corpos receptores. Para a remoção desses contaminantes tem sido empregados processos eletrolíticos, físicos e químicos, que em geral utilizam coagulantes inorgânicos de sais metálicos. O processo de eletrofloculação foi usado para o tratamento das águas residuais da etapa de purificação do biodiesel. Esse processo foi realizado em um reator eletroquímico constituído de dois eletrodos retangulares de ferro. Os eletrodos foram fixados em um becker de $250 \mathrm{~mL}$ através de uma estrutura, separados entre si por $5,3 \mathrm{~cm}$, sendo esta distância mantida constante em todos os ensaios, e a eles foram soldados fios que se ligam à fonte geradora de corrente contínua de intensidade 1,2 A. Variou-se a voltagem e o tempo de exposição ao tratamento. Após o tratamento, a amostra foi submetida a um processo de filtração em um filtro de leito fixo. Parâmetros como turbidez, cor aparente, DQO, DBO e óleos e graxas foram avaliados antes e após tratamento. A água residual após o tratamento foi reutilizada no processo de lavagem do biodiesel.

Palavras-chave: Biodiesel, Águas residuais, Eletrofloculação.

Abstract. Purification and reuse of wastewater in the production of biodiesel employing electroflocculation. In biodiesel production, the wastewater, mainly composed of glycerin, alcohol, traces of the catalyst, and other contaminants that prevent their discharge to the environment, are the most abundant. For the removal of these contaminants, have been employed electrolytic and physical-chemical processes utilizing, in general, inorganic coagulants of metallic salts. The process of electroflocculation was used for the treatment of wastewater at the stage of purifying biodiesel. This process was realized in an electrochemical reactor constituted by two rectangular iron electrodes. The electrodes were fixed on a $250 \mathrm{~mL}$ becker
Recebido: 07/05/2014

Aceito: 07/06/2015

Publicado: 30/06/2015

Acesso Aberto Artigo completo

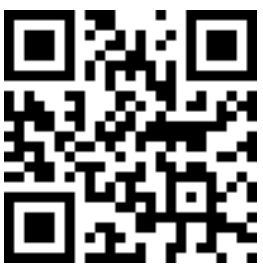


through a structure, separated by $5.3 \mathrm{~cm}$ - this distance was kept constant during all trials - and to them were soldered wires which are linked to a generator that has a continuous intensity $1.2 \mathrm{~A}$ current. Voltage and time of exposure to the treatment was varied. After the treatment, the sample was submitted to a process of filtration in a fixed bed filter. Parameters such as turbidity, apparent color, COD, BOD, oils and greases were evaluated before and after treatment. The residual water after treatment was reused in the process of washing the biodiesel.

Keywords: Biodiesel, Wastewater, Electroflocculation.

\section{Introdução}

O biodiesel pode ser obtido a partir de óleos vegetais, gorduras animais, óleos residuais e algas, todavia apesar de suas inúmeras vantagens ambientais, sua produção envolve sérios inconvenientes, dentre os quais podemos citar a produção de efluentes, provenientes dos processos de purificação, que envolvem as etapas de lavagem, filtração e secagem do produto final (Knothe et al., 2006). A etapa de lavagem no processo de produção do biodiesel é uma das mais importantes e críticas, pois tem como objetivo a retirada de resíduos de naturezas distintas, como alcoóis, glicerina, catalisador e do próprio óleo usado como matéria-prima (Guimarães, 2013). Nesta purificação, o biodiesel utiliza em média um volume três vezes maior de água a cada litro produzido, o efluente resultante do processo se torna quimicamente impróprio a ser despejado em qualquer corpo hídrico (Brito et al., 2012). O impacto ambiental causado por tais tipos de efluentes é de avaliação difícil, por causa da variedade de compostos oriundos da matéria-prima, reagentes, produtos e subprodutos do processo (Grangeiro, 2009).

Segundo Boni et al. (2007), em geral, os efluentes da etapa de purificação de biodiesel apresentam elevada presença de óleos vegetais e outros contaminantes e seu descarte indevido acarretará em um maior custo no tratamento do esgoto dessa região. Um possível descarte in natura causaria impactos nocivos ao meio ambiente (Braga, 2012). Portanto, torna-se imprescindível um tratamento desta água residuária com possível reaproveitamento nas usinas de biodiesel, ou para seu tratamento posterior por processo biológico em estações de tratamento de esgotos (Guimarães, 2013).

O tratamento da água de lavagem na produção de biodiesel pode ser feito pela aplicação de processos físicos, biológicos, químicos ou eletroquímicos, tais como a filtração, adsorção, eletrofloculação, coagulação, oxidação avançada, decantação e floculação (Brito et al., 2012). Dentre esses processos, destaca-se a eletrofloculação, que se utiliza de uma eletrólise para separação entre os resíduos e a água, com posterior filtração (Goldani et al., 2008). A separação por esse método é simples e eficiente, garantindo as especificações necessárias de redução de resíduos, como determina a Resolução Conama $n^{\circ}$ 357/2005, alterada pela Resolução Conama $n^{\circ}$ 430/2011 (Brasil, 2005, 2011; Bacelar Júnior, 2012).

No presente trabalho, a água de lavagem oriunda da etapa de purificação de um biodiesel produzido a partir do óleo de soja por transesterificação básica usando $\mathrm{KOH} / \mathrm{CH}_{3} \mathrm{OH}$ foi tratada via eletrofloculação com eletrodos de ferro. Foram avaliados os efeitos do tratamento na pósprimeira lavagem com variação da voltagem e do tempo de exposição do efluente no processo de eletrofloculação, visando a redução do $\mathrm{pH}$, turbidez, $\mathrm{DBO}_{5}$, DQO, cor aparente, óleos e graxas, segundo a Resolução Conama $n^{\circ} 357 / 2005$, alterada pela Resolução Conama n 430/2011, para água descartadas em cursos hídricos (Brasil, 2005, 2011).

A água de lavagem utilizada para avaliação do tratamento via eletrofloculação foi obtida durante a purificação do biodiesel metílico produzido a partir do óleo de soja por transesterificação alcalina em presença de $\mathrm{KOH}$. A célula eletrolítica para operação foi montada em recipiente de 
vidro, com eletrodos de ferro retangulares, com $3 \mathrm{~mm}$ de espessura, $19 \mathrm{~mm}$ de largura e comprimento médio de $97 \mathrm{~mm}$. E uma fonte alimentadora (B\&K Precision, modelo 1900), com 1,2 A. Os compostos químicos como metanol, hidróxido de sódio e ácido clorídrico com 99\% de pureza, usados na preparação do biodiesel, foram obtidos junto a VETEC (Sigma-Aldrich, Brasil).

\section{Produção do biodiesel}

O biodiesel metílico do tipo B100 foi produzido através da reação de transesterificação alcalina do óleo de soja em presença de $\mathrm{KOH}$, com razão molar óleo:metanol de 1:6. O processamento foi desenvolvido em reator de vidro (Marconi, modelo MA502/5/C, volume útil: 1 L) com controle de temperatura e agitação mecânica (impelidor do tipo pás), nas condições operacionais de $50^{\circ} \mathrm{C}, 1 \mathrm{~atm}$, $300 \mathrm{rpm}$ e tempo reacional de $1 \mathrm{~h}$. Em seguida, procedeu-se a separação da glicerina da mistura reacional via decantação. A fase mais leve da mistura contendo o B100, o catalisador e o excesso de metanol, passou pela etapa de purificação que constou de uma lavagem ácida com solução de ácido clorídrico $0,5 \mathrm{M}$. Lavagens posteriores foram realizadas com água destilada. A secagem do biodiesel foi realizada em evaporador rotativo (IKA, modelo RV10), com vidraria vertical.

\section{Dispositivo de eletrofloculação}

O tratamento da água proveniente da purificação foi realizado em um reator eletroquímico operado em batelada (béquer de vidro, volume útil $250 \mathrm{~mL}$ ) constituído de dois eletrodos de ferro de geometria retangular com $0,3 \mathrm{~cm}$ de espessura, $1,9 \mathrm{~cm}$ de largura e comprimento médio de 9,7 cm (Figura 1). A distância entre ambos foi de $5,3 \mathrm{~cm}$, sendo mantida constante durante todos os ensaios. Com os eletrodos fixados no reator através de uma estrutura metálica, e fios de cobre ligados a uma fonte de corrente contínua (1,2 A). Foi produzido um volume de $1.500 \mathrm{~mL}$ de água de lavagem (primeira lavagem) do efluente bruto, sendo avaliadas as variáveis físicas e químicas (pH, turbidez, cor, DQO, $\mathrm{DBO}_{5}$, óleos e graxas). Alíquotas de $145 \mathrm{~mL}$ do efluente bruto foram testadas de modo que a voltagem foi mantida constante e o tempo de exposição ao processo de eletroflocuação variável (10, 15 e $20 \mathrm{~min}$ ), sendo posteriormente o efluente resultante do processo de eletrofloculação filtrado, onde foram determinadas as variáveis físicas e químicas anteriormente descritas.

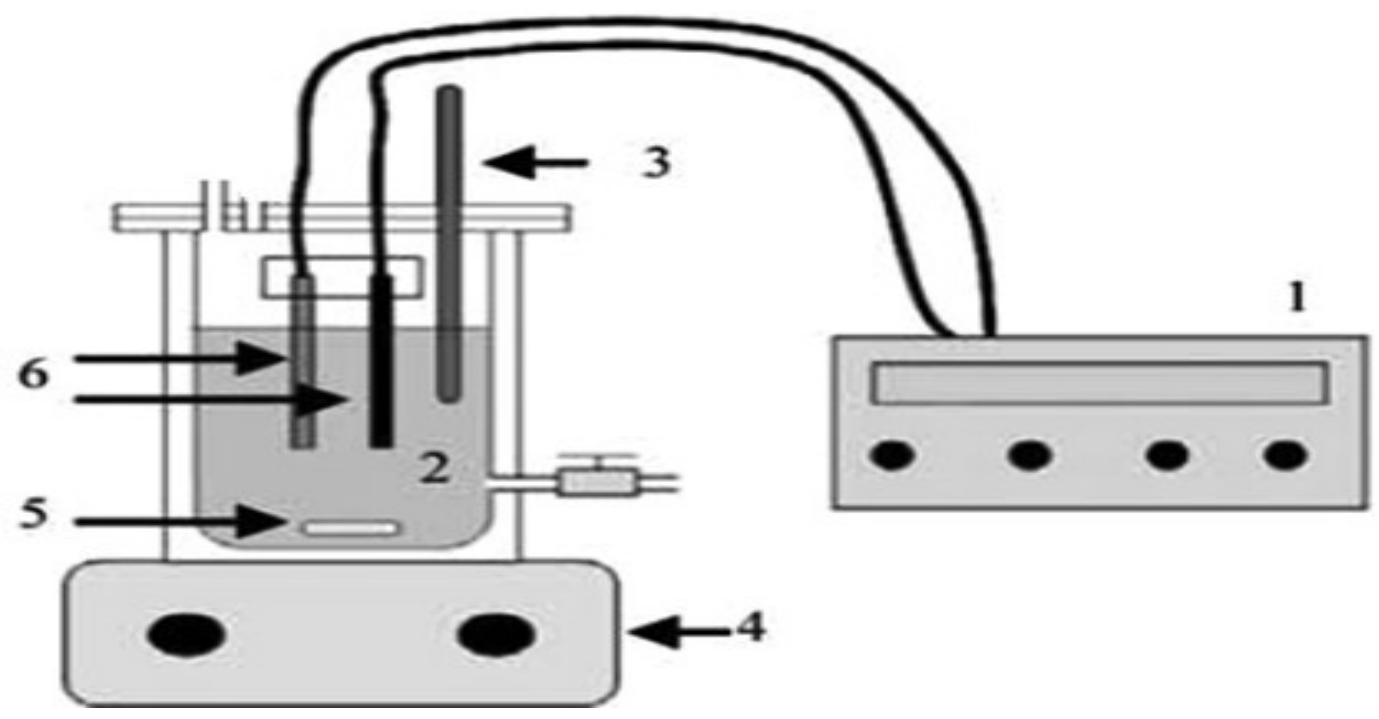

Figura 1. Esquema de montagem do reator eletroquímico para eletrofloculação da água de lavagem do biodiesel: (1) fonte alimentadora de corrente contínua, (2) eletrólito, (3) termômetro, (4) agitador magnético, (5) barra magnética, (6) eletrodos. Fonte: Adaptada de Goldani et al. (2008). 
Após cada teste, ocorreu a pesagem dos eletrodos antes e depois, a cada processo eletroquímico, tendo assim o peso médio relativo antes e após o processo na primeira eletrofloculação.

\section{Dispositivo de filtração}

O processo de filtração foi operado em um filtro de leito fixo (volume útil 1,0 L) com fluxo descendente, preenchido com camadas de areia grossa, areia fina, britas e carvão ativado, conforme apresentado na Figura 2. Foram usadas massas iguais de $10 \mathrm{~g}$ em todas as camadas de material filtrante.
pH

Os valores de $\mathrm{pH}$ das soluções bruta e pós-tratamento das águas de lavagem do biodiesel foram medidos via pHmetro digital (Quimis, modelo Q400AS), devidamente calibrado a $24^{\circ} \mathrm{C}$ (Eaton et al., 2005).

\section{Turbidez}

As medidas de turbidez foram realizadas via método nefelométrico (Eaton et al., 2005) em turbidímetro de bancada (Turbidímetro multiprocessado DLM 2000B, Del Lab®).

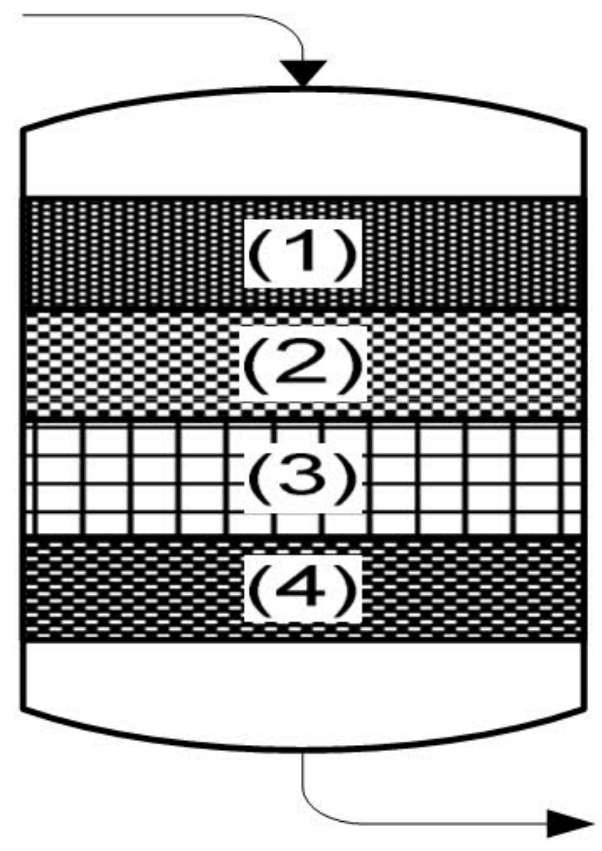

Figura 2. Filtro de leito fixo com fluxo descendente para filtração da água de lavagem póseletrofloculação: (1) areia grossa, (2) areia fina, (3) britas, (4) carvão ativado.

\section{$\mathrm{DBO}_{5}$ e DQO}

As análises de DQO foram realizadas via método colorimétrico (Standard Methods 5220 D) (Eaton et al., 2005), com bloco digestor do tipo TE-021 Dry Block Digestor (TECNAL). A DQO nas amostras foi quantificada por espectrofotometria (Spectrophotometer SP1105, Bel Photonics), tomando-se como branco um padrão de água destilada (BioClass).
As análises de $\mathrm{DBO}_{5}$ recorreram ao método definido no Standard Methods 5210 B (Eaton et al., 2005), com determinação quantitativa posterior das amostras em um oxímetro (Digimed, modelo: DM-4D).

\section{Cor aparente}

As medidas de cor aparente das águas de lavagem foram realizadas usando a metodologia modificada de Eaton et al. (2005), através de leituras espectrofotométrica de UV (Spectrophotometer 
SP2000UV, Bel Photonics) a $546 \mathrm{~nm}$. O comprimento de ondas foi escolhido com base no trabalho de Ladchumananandasivam (2004).

\section{Óleos e graxas}

Para a determinação do teor de óleos e graxas utilizou-se o método gravimétrico por meio de extração líquidolíquido (Eaton et al., 2005). As amostras foram acidificadas com ácido sulfúrico, a fim preservá-las, bem como favorecer a hidrólise ácida no meio. Em um funil de separação, contendo a amostra acidificada, foram colocados $100 \mathrm{~mL}$ de éter de petróleo, seguindo uma agitação por 5 min. Após a separação das fases, o solvente foi levado para uma coluna de carbonato de cálcio, a fim de retirar todo resíduo aquoso. Em seguida, o solvente foi transferido para uma cápsula de porcelana previamente preparada a peso constante e levado a uma estufa de secagem e esterilização da Fanem, modelo 320 - SE, a $70^{\circ} \mathrm{C}$, para evaporação de todo o solvente até permanecer a fase oleosa. Em seguida a cápsula de porcelana foi levada ao dessecador por 30 min e após o resfriamento foram pesadas. A massa de óleos e graxas foi calculada por diferença de pesagem das cápsulas antes e após o procedimento de extração.

\section{Resultados e discussão}

Os resultados da caracterização da água de lavagem pós-purificação do biodiesel metílico de soja $(\mathrm{pH}$, turbidez, $\mathrm{DBO}_{5}, \mathrm{DQO}$, cor aparente, óleos e graxas) e após o tratamento por eletrofloculação estão apresentados na Tabela 1, para a DDP constante de $7,5 \mathrm{~V}$, e na Tabela 2 estão representados os mesmos parâmetros para a DDP 12,0 V.

De acordo com Fornari (2007), a eletrofloculação nada mais é, que um processo de coagulação, o qual necessita de um reator eletroquímico (eletrodo de ferro ligado a uma corrente elétrica continua). Nesse processo, a corrente elétrica, que é ligada a um eletrodo (catodo e anodo), ajuda na oxidação do anodo, estando o catodo sujeito à redução do elemento metálico e no consequente aumento das partículas (liberação de elétrons de ferro no processo), fazendo a interconexão com as substâncias indesejadas encontrada na água de purificação do biodiesel (formação de microbolhas de hidrogênio a partir do cátodo), dando origem aos fenômenos de floculação e decantação, o qual facilita a posterior filtração (Borba, 2010).

Santos et al. (2006) evidencia a eficiência do processo eletroquímico na tratabilidade dos efluentes das industrias de óleo. Crespilho e Rezende (2004) divide o

Tabela 1. Características físico-químicas dos efluentes bruto e tratado via eletrofloculação (DDP 7,5 V).

\begin{tabular}{|c|c|c|c|c|c|c|}
\hline \multicolumn{7}{|c|}{ Tempo de Exposição ao Tratamento = 10 min } \\
\hline Água & pH & $\begin{array}{l}\text { Turbidez } \\
\text { (NTU) }\end{array}$ & $\begin{array}{l}\text { Cor Aparente } \\
\text { (UC) }\end{array}$ & $\begin{array}{l}\text { DQO } \\
(\mathrm{mg} / \mathrm{L})\end{array}$ & $\begin{array}{c}\mathrm{DBO}_{5} \\
(\mathrm{mg} / \mathrm{L})\end{array}$ & $\begin{array}{l}\text { Óleos e } \\
\text { Graxas } \\
\text { (mg/L) }\end{array}$ \\
\hline $\begin{array}{l}\text { Primeira lavagem } \\
\text { (efluente bruto) }\end{array}$ & 3,04 & 68,4 & 0,286 & $5.293,85$ & $4.920,20$ & 68 \\
\hline $\begin{array}{l}\text { Eletrofloculação (pós- } \\
\text { primeira lavagem) }\end{array}$ & 5,57 & 0,026 & 0,053 & $1.842,75$ & $1.949,70$ & 47 \\
\hline $\begin{array}{l}\text { Resolução Conama } n^{\circ} \\
430 / 2011\end{array}$ & 5 a 9 & Até 40 & $\begin{array}{l}\text { Nível natural } \\
\text { do corpo } \\
\text { receptor }\end{array}$ & - & $\begin{array}{c}\text { Remoção } \\
\text { mínima de } \\
60 \% \\
\end{array}$ & 50 \\
\hline \multicolumn{7}{|c|}{ Tempo de Exposição ao Tratamento = 15 min } \\
\hline $\begin{array}{l}\text { Eletrofloculação (pós- } \\
\text { primeira lavagem) }\end{array}$ & 5,56 & 0,18 & 0,006 & $2.575,14$ & $1.819,32$ & 35 \\
\hline \multicolumn{7}{|c|}{ Tempo de Exposição ao Tratamento = 20 min } \\
\hline $\begin{array}{l}\text { Eletrofloculação (pós- } \\
\text { primeira lavagem) }\end{array}$ & 6,74 & 6,43 & 0,024 & $3.307,53$ & $1.644,22$ & 25 \\
\hline
\end{tabular}


Tabela 2. Características físicas e químicas dos efluentes bruto e tratado via eletrofloculação (DDP $12,0 \mathrm{~V})$.

\begin{tabular}{|c|c|c|c|c|c|c|}
\hline \multicolumn{7}{|c|}{ Tempo de Exposição ao Tratamento = 10 min } \\
\hline Água & pH & $\begin{array}{c}\text { Turbidez } \\
\text { (NTU) }\end{array}$ & $\begin{array}{l}\text { Cor Aparente } \\
\text { (UC) }\end{array}$ & $\begin{array}{c}\text { DQO } \\
\text { (mg/L) }\end{array}$ & $\begin{array}{c}\mathrm{DBO}_{5} \\
\text { (mg/L) }\end{array}$ & $\begin{array}{l}\text { Óleos e } \\
\text { Graxas } \\
\text { (mg/L) }\end{array}$ \\
\hline $\begin{array}{l}\text { Primeira lavagem } \\
\text { (efluente bruto) }\end{array}$ & 3,04 & 68,4 & 0,286 & $5.293,85$ & $4.920,20$ & 68 \\
\hline $\begin{array}{l}\text { Eletrofloculação } \\
\text { (pós-primeira } \\
\text { lavagem) }\end{array}$ & 6,71 & 0,86 & 0,006 & $4.051,01$ & 1964,11 & 49 \\
\hline $\begin{array}{l}\text { Resolução Conama } \\
\text { n 430/2011 }^{\circ}\end{array}$ & 5 a 9 & Até 40 & $\begin{array}{l}\text { Nível natural } \\
\text { do corpo } \\
\text { receptor }\end{array}$ & - & $\begin{array}{c}\text { Remoção } \\
\text { mínima de } \\
60 \%\end{array}$ & 50 \\
\hline \multicolumn{7}{|c|}{ Tempo de Exposição ao Tratamento = 15 min } \\
\hline $\begin{array}{l}\text { Eletrofloculação } \\
\text { (pós-primeira } \\
\text { lavagem) }\end{array}$ & 6,41 & 7,59 & 0,006 & $2.641,72$ & $1.223,88$ & 38 \\
\hline \multicolumn{7}{|c|}{ Tempo de Exposição ao Tratamento = 20 min } \\
\hline $\begin{array}{l}\text { Eletrofloculação } \\
\text { (pós-primeira } \\
\text { lavagem) }\end{array}$ & 6,24 & 8,25 & 0,077 & $2.303,27$ & $1.187,02$ & 21 \\
\hline
\end{tabular}

processo de eletrofloculação em quatro etapas (geração eletroquímica do agente coagulante, eletrocoagulação, eletrofloculação e por fim, flotação das impurezas ou eletroflotação), mostrando bem que o processo de eletrofloculação tem a característica de varredura em estação de tratamentos de efluentes (ETE), o qual faz a ocorrência dos fenômenos de floculação e decantação, para facilitar o processo de filtração, para remoção significativa das partículas indesejadas.

Nesta pesquisa pode-se observar que o processo sem tratamento por eletrofloculação, tem um baixo valor de $\mathrm{pH}$ para a água oriunda da primeira lavagem, na purificação do biodiesel produzido, situado fora das especificações exigidas pela legislação. Destaca-se também que o teor de óleos e graxas na primeira lavagem, apresentou um valor elevado, fora do exigido para descarte em corpos hídricos. A cor aparente da água após lavagem, em comparação com o padrão, encontrou-se dentro das especificações exigidas pela legislação para descarte (Resolução Conama no 430/2011), bem como a DQO e a $\mathrm{DBO}_{5}$.

A primeira lavagem serviu à equalização do efluente para descarte, contudo mantendo-o ainda fora dos padrões especificados. Considerando uma única etapa de lavagem com água destilada depois da lavagem ácida, não é possível o descarte direto em cursos hídricos sem tratamento prévio segundo as especificações exigidas na Resolução Conama $\mathrm{n}^{\circ}$ 430/2011, bem como é improvável o reuso do efluente hídrico no processo de produção do biocombustível.

Aplicando o tratamento via eletrofloculação após primeira lavagem do biodiesel, observou-se o estabelecimento das condições indicadas pela legislação para descarte, confirmando assim a eficiência apontada por Santos et al. (2006). O pH da água de lavagem situou-se próximo da neutralidade, dentro das especificações indicadas, bem como foi possível observar a redução significativa na turbidez (90,6\%), DQO (37,5\%), $\mathrm{DBO}_{5}(66,6 \%)$, óleos e graxas (63,2\%), tais percentuais de redução foram obtidos com base no efluente bruto após a primeira lavagem e o tratamento de eletrofloculação com tempo de exposição ao tratamento de $20 \mathrm{~min}$, com DDP em $7,5 \mathrm{~V}$.

Para a economia energética no processo de eletrofloculação, destaca-se o que perdurou por 10 min com DDP em 7,5 V, o 
qual obteve valores semelhantes a exposição por $20 \mathrm{~min}(\mathrm{pH}$ dentro das especificações e as variáveis com remoção significativa, sendo eles turbidez (99,96\%), cor aparente (81,66\%), DQO (65,19\%), $\mathrm{DBO}_{5}(60,37 \%)$ e óleos e graxas $(30,88 \%)$ ).

Na Tabela 2, observa-se que se elevando o valor da DDP para $12,0 \mathrm{~V}$ e repetindo as condições experimentais anteriores, com relação ao tempo de exposição ao tratamento por eletrofloculação, foi possível observar a redução significativa na turbidez (87,9\%), DQO (56,5\%), $\mathrm{DBO}_{5}$ (75,9\%), óleos e graxas $(69,1 \%)$, no tempo de 20 min. Tais resultados mostram que, com relação ao tratamento por eletrofloculação, a redução significativa de variáveis, como DBO e DQO, indicam que quanto maior a DDP aplicada nos terminais dos eletrodos, bem como, quanto maior o tempo de exposição do efluente ao processo de tratamento, maior será redução das variáveis físicas e químicas, que tornam o efluente aptos ao descarte aos corpos hídricos segundo a legislação brasileira atual.

Vale salientar que as águas que se encontram com a turbidez abaixo de 6 NTU (tempo de exposição do tratamento entre 10 e 15 min, para $7,5 \mathrm{~V}$, e 10 min para $12 \mathrm{~V}$ ), estão aptas para reuso no processo de produção do biodiesel. Tanto na Tabela 1, quanto na Tabela 2 , pode ser observado que, quanto maior o tempo de exposição e a tensão elétrica aplicada, maiores foram observados os valores de turbidez. Isto se deve à depuração do eletrodo de ferro no processo, o que implica em complicações no reuso da tratabilidade do mono-ester, ficando com excesso de ferro e inapto para, consumo de acordo com a Resolução ANP $n^{\circ}$ 45/2014 (ANP, 2014).

Fornari (2007) chama a atenção para o controle no processo de eletrofloculação, visando a um resultado final mais eficiente, lembrando que o controle da condutividade da solução, a resistividade do meio, o potencial aplicado entre os eletrodos e a corrente obtida são essenciais neste processo. Monitorar as variáveis, como o tempo reacional e a voltagem aplicada no processo, implica no controle reacional dos metais carregados positivamente, que reagem com as partículas negativas dos efluentes, garantindo assim eficácia no produto final (Chen, 2004).

\section{Conclusão}

Os resultados obtidos indicaram que antes da aplicação do tratamento, tanto o efluente bruto, quanto aquele derivado da primeira lavagem, não poderiam ser devolvidos aos corpos hídricos por estarem fora das especificações exigidas pela legislação.

A aplicação da eletrofloculação após a primeira lavagem atendeu aos critérios de devolução da água de lavagem conforme as especificações, tendo apresentado redução na turbidez $(99,96 \%)$, cor aparente (81,66\%), DQO (65,19\%), $\mathrm{DBO}_{5}$ $(60,37 \%)$ e óleos e graxas $(30,88 \%)$, para um tempo de exposição ao tratamento de 10 min e diferença de potencial de $7,5 \mathrm{~V}$, o qual garante um consumo energético menor que os demais, aliada a uma depuração controlada do eletrodo de ferro, pode dar a água de lavagem as condições necessárias para serem reaproveitadas no processo de produção do biodiesel, como também esta apta para o descarte nos corpos hídricos atendendo as determinações da Resolução Conama n 430/2011.

\section{Declaração de conflito de interesses}

conflitos de interesses.

\section{Referências}

ANP - Agência Nacional do Petróleo, Gás Natural e Biocombustíveis. Resolução no 45, de 25 de agosto de 2014. Disponível em: $<$ http://nxt.anp.gov.br/NXT/gateway.dll/leg/ resolucoes_anp/2014/agosto/ranp $45 \quad$ 2014.xml>. Acesso em: 14 abr. 2015.

Bacelar Júnior, A. C. Tratamento fotocatalítico $\left(\mathrm{TiO}_{2} / \mathrm{UV}\right)$ de águas ácidas de lavagem de biodiesel. São Carlos: Universidade de São Paulo, Instituto de Química de São Carlos, 2012.

Boni, L. A. B.; Goldani, E.; Milcharek, C. D.; Santos, F. A. Tratamento físico-químico da água de lavagem proveniente da purificação do biodiesel. Periódico Tchê Química, v. 4, n. 7, p. 41-50, 2007. Disponível em: <http://www.deboni.he.com.br/revista7.pdf>. Acesso em: 14 abr. 2015.

Borba, F. H. Aplicação dos processos fotofenton e eletrofloculação no tratamento de efluente de curtume. Toledo: Universidade 
Estadual do Oeste do Paraná, 2010. (Dissertação de Mestrado).

Braga, E. D. A. S. Caracterização das águas de lavagem provenientes da etapa de purificação da produção de biodiesel de óleo de tilápia. Fortaleza: Universidade Federal do Ceará, 2012. (Dissertação de Doutorado).

Brasil. Leis, Decretos, etc. Resolução CONAMA no 357, de 17 de março de 2005. Dispõe sobre a classificação dos corpos de água e diretrizes ambientais para 0 seu enquadramento, bem como estabelece as condições e padrões de lançamento de efluentes, e dá outras providências. Disponível em: <http://www.mma.gov.br/port/conama/res/res05 /res35705.pdf>. Acessado em: 14 abr. 2015.

Brasil. Leis, Decretos, etc. Resolução CONAMA $n^{\circ}$ 430, de 13 de maio de 2011. Dispõe sobre as condições e padrões de lançamento de efluentes, complementa e altera a Resolução no 357, de 17 de março de 2005, do Conselho Nacional do Meio AmbienteCONAMA. Disponível em: $<$ http://www.mma.gov.br/port/conama/ legiabre.cfm?codlegi=646>. Acessado em: 14 abr. 2015.

Brito, J. F.; Ferreira, L. O.; Silva, J. P.; Ramalho, T. C. Tratamento da água de purificação do biodiesel utilizando eletrofloculação. Quím. Nova, v. 35, n. 4, p. 728-732, 2012.

Chen, G. Electrochemical technologies in wastewater treatment. Separation and Purification Technology, v. 38, p. 11-41, 2004.

Crespilho, F. N.; Rezende, M. O. O. Eletroflotação: princípios e aplicações. 1 ed. São Carlos: Rima, 2004.

Eaton, A. D.; Clesceri, L. S.; Rice, E. W.; Greenberg, A. E.; Franson, M. A. H. (Ed.). Standard methods for the examination of water and wastewater. 21. ed. Washington,
D.C.: American Public Health Association, 2005.

Fornari, M. M. T. Aplicação da técnica de eletro-floculação no tratamento de efluentes de curtume. Toledo: Universidade Estadual do Oeste do Paraná, 2010. (Dissertação de Mestrado).

Goldani, E.; Boni, L. A. B.; Frankenberg, C. L. C.; Cantelli, M. Tratamento físicoquímico dos efluentes líquidos provenientes da purificação do biodiesel. Pelotas: Embrapa Clima Temperado, 2008.

Grangeiro, R. V. T. Caracterização da água de lavagem proveniente da purificação do biodiesel. João Pessoa: Universidade Federal da Paraíba, 2009. (Dissertação de Mestrado).

Guimarães, P. S. Tratamento de águas residuárias oriundas da purificação do biodiesel por coagulação empregando sulfato de alumínio e quitosana: avaliação Preliminar. Brasília: Universidade de Brasília, 2013. (Dissertação de Mestrado).

Knothe, G.; van-Gerpen, J.; Pereira, L.; Krahl, J. Manual de biodiesel. San José, Costa Rica: IICA, 2006.

Ladchumananandasivam, R. Processos químicos têxteis. Volumem II - Ciência da cor. Natal: Universidade Federal do Rio Grande do Norte, 2004. Disponível em: <http://clovisbezerra. tripod.com/materiais-didaticos/proquiii/ciencia-da-cor.pdf> $>$. Acesso em: 14 abr. 2015. Santos, M. R. G.; Goulart, M. O. F.; Tonholo, J.; Zanta, C. L. P. S. The application of electrochemical technology to the remediation of oily wastewater. Chemosphere, v. 64, p. 393-399, 2006. 
Informação da Licença: Este é um artigo Open Access distribuído sob os termos da Licença Creative Commons Attribution, que permite uso irrestrito, distribuição e reprodução em qualquer meio, desde que a obra original seja devidamente citada.

Rev. Bras. Gest. Amb. Sustent., 2015, v. 2, n. 2, p. 51-58. 